\title{
21st Century Stock Market: A Regulatory Model for Daily Fantasy Sports
}

\begin{abstract}
Alicia Jessop*
The popularity of daily fantasy sports contests has risen exponentially as daily fantasy sports providers have raised hundreds of millions of dollars in seed funding from major sport industry and media stakeholders. Among this industry rise, concerns over whether the industry's consumer protection mechanisms are stringent enough have arisen. In response, individual states executed varied approaches to regulate the industry within their borders. Some have imposed complete bans, while few allow the industry to widely operate and others have imposed significant regulations. States' responses to the daily fantasy sports industry are akin to state legislators' regulation of the securities industry in the 20th century. This paper analyzes state and federal regulations imposed on the securities industry in the 20th century to provide an argument as to why federal regulation of the daily fantasy sports industry is necessary.
\end{abstract}

\section{Introduction}

A new force in advertising, fan engagement, and corporate sponsorship emerged at the start of the 2015 National Football League (NFL) season: daily fantasy sports. Lucrative rounds of investment funding backed by leading media entities, including NBC Sports, Comcast Ventures, TimeWarner/Turner Sports, and Fox Sports, allowed daily fantasy sports providers (FanDuel and DraftKings) to bullishly compete in the marketplace for new users.

Armed with \$362.5 million (Heitner, 2015) and \$626 million ("Legal Sports Report," 2015) in seed money, respectively, FanDuel and DraftKings inundated American television viewers with advertising early in the 2015 NFL season. During the first week of the 2015 season alone, FanDuel spent $\$ 13.7$ million in advertising, while DraftKings spent $\$ 16.6$ million (Baker, 2015). Given the two companies' 2015 television ad buy topping $\$ 500$ million, it's not surprising that for a period of time in the same year, a DraftKings or FanDuel advertisement aired on television every 90 seconds (Berzon, 2016; Van Natta Jr., 2016).

Beyond aggressive advertising campaigns, both DraftKings and FanDuel executed successful corporate sponsorship campaigns. Leading up to and during

\footnotetext{
"Alicia Jessop, JD, is an assistant professor in the Communication Division at Pepperdine University; email: alicia.jessop@pepperdine.edu
} 
2015, DraftKings signed multiyear partnership agreements with Major League Baseball (MLB) and the National Hockey League (NHL), while FanDuel negotiated a multiyear deal with the National Basketball Association (NBA). Although to date the NFL as a league has not signed an exclusive partnership agreement with any daily fantasy sports provider, NFL teams have joined teams across other leagues in negotiating exclusive partnerships with daily fantasy sports providers (“Legal Sports Report,” 2016).

For daily fantasy sports providers like DraftKings and FanDuel, these multi-faceted advertising and marketing campaigns aimed at acquiring control of the market share of daily fantasy sports players have led to a vast rise in daily fantasy sports participation. Altogether, the fantasy sports industry has grown 100 -fold over the last 30 years, with 56.8 million people in North America participating in contests. Daily fantasy sports have played a significant role in this growth. The estimated \$3.7 billion consumers spent in 2015 to participate in daily fantasy sports contests was greater than the amount wagered on season-long fantasy sports contests (Fantasy Sport Trade Association, 2015; Hall, 2015).

In the wake of the growing popularity of daily fantasy sports, concerns have emerged over whether appropriate consumer protection mechanisms exist within the industry. Focus on whether consumers wagering on daily fantasy sports sites are adequately protected came to a head in October 2015, when allegations of insider trading arose against DraftKings and FanDuel. The insider trading allegations came after a DraftKings employee accidentally released player-related data before the time scheduled for its release. The same week, that employee won $\$ 350,000$ playing daily fantasy sports on competing site FanDuel (Drape \& Williams, 2015). DraftKings investigated the insider trading allegations involving its employee and found no improprieties. Subsequently, both DraftKings and FanDuel banned daily fantasy sports providers' employees, including their own, from competing in contests (Needleman \& Terlep, 2015).

Subsequent to the allegation of insider trading, DraftKings and FanDuel announced plans to merge in November 2016 (Drape, 2016). However, the merger was called off in July 2017, presumably because of antitrust law concerns (Purdum, 2017). Other smaller daily fantasy sports sites have raised concerns over the two entities' apparent control over the marketplace, as DraftKings and FanDuel control $95 \%$ of the daily fantasy sports market (Edelman, 2017.)

Insider trading and potential monopoly concerns are part of a longer list of consumer protection concerns related to the daily fantasy sports industry. In 2016 alone, the industry was faced with concerns over stacking, addiction, lack of proper age verification of players, and claims of false advertising (Galka, 2015; Harwell, 2015; Rovell, 2015; Satariano, 2015; Terlep, 2015; Woodward, 2016). Those researching the industry have also questioned whether consumers have adequate information to discern the risks of competition and strengths of the competitors they compete against (Daily Fantasy Sports: Issues and Perspectives, 2016).

To date, individual states have taken varied approaches to addressing the legality of daily fantasy sports within their borders. Some states have declared participation in daily fantasy sports contests illegal, while others have ruled the contests legal within their borders. Many states legalizing daily fantasy sports 
have subsequently regulated the industry. However, the states that have regulated the industry lack a uniform regulatory model. The notable variations between states' regulatory models for the daily fantasy sports industry creates consumer protection concerns (Daily Fantasy Sports: Issues and Perspectives, 2016; Edelman, 2015, 2017; Legal Sport Report, 2016; Whaley, 2016; Woodward, 2016).

Given the lack of consistency in state regulatory frameworks for the daily fantasy sports industry and the industry's engagement in interstate commerce, this article addresses the need for federal regulation of the daily fantasy sports industry. It looks to the similarities between the securities industry in the 20th century and the daily fantasy sport industry in the 21 st century to propose a model federal regulatory structure aimed at securing consumer protection for daily fantasy sports players.

Section I discusses the rise of the securities industry in the United States in the early 20th century, identifies the issues precipitating adoption of securities-related state and federal consumer protection mechanisms, and outlines relevant state and federal securities laws. Section II discusses the state regulations that have been enacted for the daily fantasy sports industry. Section III compares the 20 th century securities industry to the 21 st century daily fantasy sports industry to highlight the need for federal regulation of the daily fantasy sports industry. Section IV proposes a model federal framework for regulating the daily fantasy sports industry.

\section{Regulation of the United States Securities Industry}

\section{A Brief History of the Securities Industry in the United States}

The American economy experienced a period of significant growth during the early 20th century due to the rise of the railroad and manufacturing industries. This economic growth meant that members of the American middle class had greater amounts of wealth to use as capital for the purchase of bonds, stocks, and other securities. The dichotomy of the growing American industrial economy and rising American middle class paved the way for issuance of increased numbers of securities (Macey \& Miller, 1991).

While most securities issued "were reputable and safe ... plenty of speculative issues were available in the market." Speculative securities could not be traded on the standard stock exchanges. Thus, their purveyors relied upon advertising ranging from "face to face solicitation, newspaper advertisements and mass mailings" to attract purchasers (Macey \& Miller, 1991, p. 353).

As Americans turned to speculative securities investments in growing numbers, "intense public concern about fraudulent promotions" arose. Additionally, some worried that advertisements highlighting speculative securities promoted "get-rich-quick" schemes, while others took issue with investors removing money from the local bank to invest it with "a stranger who offers ... something that is ... plausibly presented but which violates all ... previous prejudices ..." (Macey \& Miller, 1991, pp. 355-358).

During the early 20th century, states began regulating the securities industry through passage of laws known as "blue sky laws." Yet, shortly after widespread 
enactment of blue sky laws, the United States stock market crashed in 1929. The stock market crash called into question the effectiveness of state blue sky laws to regulate the securities industry and protect consumers.

Concern over the blue sky laws' effectiveness was fueled by questions related to the transparency of information provided to Americans by corporations of the securities in which they invested (Securities and Exchange Commission, 1999). President Franklin D. Roosevelt and numerous congressmen and senators questioned the amount and validity of information provided to Americans ahead of purchasing securities. Congress asserted that the lack of information required to be provided by corporations to securities investors allowed some securities dealers to engage in fraudulent transactions. These concerns led the federal government to enact two pieces of federal legislation, the Securities Act of 1933 and Securities Exchange Act of 1934, meant to provide consumers with transparency in the purchase of securities and protect them from investing in fraudulent securities (Ellenberger \& Mahar, 1973).

\section{State Regulation of the Securities Industry: Blue Sky Laws}

Facing growing concerns over the legitimacy of speculative securities, beginning in 1911, individual states passed blue sky laws to address "serious abuses in securities markets" (Miller \& Macey, 1991, p. 348). Altogether, between 1911 and 1931, 47 states enacted blue sky laws (Mahoney, 2003).

Each state's law contained its own particularities, but several commonalities existed among blue sky laws. First, many states' blue sky laws required securities firms to become licensed and file regular financial reports. Additionally, some states' blue sky laws gave states the ability to prohibit the sale of securities identified as not promising "a fair return on the investment" (Macey \& Miller, 1991, p. 377). The constitutionality of this was challenged in various states' court systems, which resulted in many subsequent states' blue sky laws simply outlawing the sale of fraudulent securities. Ultimately, in general, blue sky laws prevented the fraudulent sale of securities, ensured that consumers had accurate information to utilize in determining whether to purchase securities, and limited consumers' losses when investing in securities with minimal opportunities for positive returns.

\section{Federal Regulation of the Securities Industry: Securities Act of 1933 and Securities Exchange Act of 1934}

Despite 47 states passing blue sky laws, widespread speculation and bilking of investors continued. The breadth of consumers' losses is demonstrated by a congressional finding that between 1918 and 1928, \$50 billion of new securities were sold, but half were valueless (H.R. Rep. No. 85, 1933). The 1929 stock market crash along with the height of the United States' economic depression in 1933 caused Americans to recognize "[t]he minimal impact of the blue sky laws ..." (Keller, 1988, p. 336). Roosevelt summarized the issue in a letter to Congress when he wrote, "In spite of many state statutes the public in the past has sustained severe losses through practices neither ethical nor honest on the part of many persons and corporations selling securities" (Ellenberger \& Mahar, 1973, p. 937). 
Lack of jurisdiction over interstate commerce and the widespread trading of securities across state lines precipitated the blue sky laws' ineffectiveness. In a hearing for what would become the Securities Act of 1933, New Jersey congressman Charles A. Wolverton argued, "The failure to prevent such losses is not due to any lack of stringency in the statutes already enacted by the several States, but, in a large measure, because of the inability of State laws to reach interstate transactions in such securities" (Ellenberger \& Mahar, 1973, p. 2931).

Ultimately, the inability of state blue sky laws to adequately regulate the securities industry led Americans to demand federal legislation to govern the securities industry (Keller, 1988). In drafting federal legislation for the securities industry, Congress did not seek to ban the sale of securities. Rather, the focus of the legislation was to grant consumers access to information to inform their decisions on investing. During a hearing on what would become the Securities Act of 1933, Michigan congressman Carl E. Mapes stated:

The bill is not foolproof. It will not prevent anybody from putting his money into rat holes or into highly speculative ventures if he sees fit to do so, but in the exercise of reasonable care he can go to the Federal Trade Commission or to the underwriter or the dealer in the securities and find out the facts relating to the business of the corporation issuing the securities, the profits which the dealers are to receive in selling them, and the amount of money that is to go back into the treasury of the corporation after the sale is made-how much of the $\$ 100$ per share, or whatever amount he pays for his stock, is really going back to the corporation, going into the treasury for the promotion of the business of the corporation. (Ellenberger \& Mahar, 1973, p. 2912)

The statement by Mapes signals a shift by Congress away from the principle of caveat emptor and toward a regulatory structure requiring corporations to provide securities purchasers with transparent information to guide their decisions. Others in Congress echoed this sentiment. Speaking at a hearing for the Securities Act of 1933, Indiana congressman Arthur H. Greenwood asserted:

There is a peculiar fact with respect to such investments in that the corporation that issues the securities knows more about them than anyone else, and the old rule of caveat emptor, or buyer beware, certainly should not apply to this character of investments. The man who sells them ought to give all the facts, and the Government ought to require the issuer of securities to give all the facts and be honest with the public. (Ellenberger \& Mahar, 1973, p. 2914)

Thus, in regulating the securities industry, Congress sought not to "interfere with," but "supplement" state blue sky laws so that it would be "impossible for dealers and underwriters to evade the State laws by the shipment of their securities and prospectuses and other material in interstate commerce ..." (Ellenberger \& Mahar, 1973, p. 2912).

As enacted, the Securities Act of 1933 requires the publishing of certain financial and other significant information before a security is offered for public 
sale. Additionally, it created a registration process for all securities sold in the United States and prohibits deceit, misrepresentation, and fraud in the sale of securities. Initially, the Securities Act of 1933 was enforced by the Federal Trade Commission (Securities Act of 1933, 1933).

In 1934, enforcement of the Securities Act of 1933 was removed from the Federal Trade Commission when Congress enacted the Securities Exchange Act of 1934. The Securities Exchange Act of 1934 created the Securities and Exchange Commission (SEC). Under the Securities Exchange Act of 1934, the SEC has the power to register, regulate, oversee, and discipline the securities industry. Additionally, the Securities Exchange Act of 1934 prohibited certain market conduct in the sale of securities and required periodic reporting by companies with publicly traded securities (Securities Exchange Act of 1934, 1934).

\section{State Regulation of the Daily Fantasy Sports Industry}

\section{The Legality of Daily Fantasy Sports in the United States}

As the popularity of and participation in daily fantasy sports contests grow, questions over the contests' legality persist. These questions are due in large part to a lack of clarity in the federal laws governing sports gambling in the United States.

In 1992, Congress passed the Professional and Amateur Sports Protection Act (PASPA). In part, PAPSA outlawed gambling operations directly or indirectly based on professional or amateur sports contests. Notably, the text of the law only bans "lotter[ies], sweepstakes, ... other betting, gambling [and] wagering scheme[s]" (Professional and Amateur Sports Protection Act, 1992, § 3702). Certain states were exempted from the law, because they had sport gambling operations in place prior to the passage of PASPA (Professional and Amateur Sports Protection Act, 1992). Thus, as of the date of this submission, there are four states in the United States in which sport gambling is legal: Oregon, Delaware, Montana, and Nevada (Millman, 2009).

Subsequent to the passage of PASPA, Congress enacted the Unlawful Internet Gambling Enforcement Act (UIGEA) in 2006. The law prohibits those "in the business of betting or wagering" from knowingly accepting funds in connection with "unlawful Internet gambling" (Unlawful Internet Gambling Enforcement Act, 2006, § 5563). In defining "bets or wagers," Congress excluded "participation in any fantasy ... sports game," so long as prizes for the contest are made known before the start of the contest, the value of prizes isn't determined by fees or participants, and "winning ... reflect[s] the ... knowledge and skill of the participants and [is] determined ... by ... [statistics] ... from multiple real-world sporting events" (Unlawful Internet Gambling Enforcement Act, 2006, § 5562). In exempting fantasy sports contests from the UIGEA, Congress also specified that the winning outcome of said contests couldn't be based on scores, pointspreads, or performances of one single team or one single athlete (Unlawful Internet Gambling Enforcement Act, 2006). 
In the advent of daily fantasy sports, Congress's exemption of fantasy sports from the purview of the UIGEA has caused confusion over whether said contests are legal under federal law. First, given that daily fantasy sports contests did not exist in 2006, it is unclear whether Congress intended to exempt this type of contest from the law's reach. Second, debate exists over whether participation in daily fantasy sports contests meets the requisite knowledge and skill required under the UIGEA exemption. Finally, it is uncertain whether daily fantasy sports contests wherein players place wagers on the real-world performances of single teams or single athletes fall within the scope of the exemption (Edelman, 2016).

As confusion exists over whether daily fantasy sports contests are legal under federal law, individual states have taken varying approaches in deciding the contests' legality within their borders. Three tests have emerged, which states apply to determine the legality of daily fantasy sport contests: the "predominant purpose test," the "material element test," and the "modicum of chance test" (Edelman, 2016).

A majority of states have adopted a version of a "predominant purpose test." Using this test, states consider whether a "contest involves more skill than chance." If a greater amount of skill is involved than chance, the contest is legal. A minority number of states have adopted a version of the "material element test." Under the material element test, states consider whether a material element of the contest depends upon an element of chance. If a material element does, the contest is deemed illegal. Finally, another minority number of states have adopted a version of the "modicum of chance test." Applying this test, states consider whether the contest contains a degree of chance. If a degree of chance is found, the contest is deemed illegal (Edelman, 2016).

Applying the test adopted by their respective state, some state legislatures have enacted statutes declaring the legality or illegality of daily fantasy sports. Other states' attorneys general have issued declaratory judgments and orders regarding the legality of daily fantasy sports contests within their borders. These statutes, declarations, and orders have run the gamut, with some states declaring the contests legal, others outlawing them, and some issuing widespread regulatory and licensing controls ("Legal Sport Report," 2016; McGreevy, 2016; Smith \& Spehler, 2016; Woodward, 2016).

\section{State Regulation of the Daily Fantasy Sports Industry}

As of 2017, 16 states have enacted legislation regulating daily fantasy sports: Arkansas, Colorado, Delaware, Indiana, Maine, Maryland, Massachusetts, Mississippi, Missouri, New Hampshire, New Jersey, New York, Pennsylvania, Tennessee, Vermont, and Virginia ("Legal Sports Report," 2017). States legalizing daily fantasy sports have taken differing approaches to regulating the industry. These differing approaches highlight potential consumer protection concerns in interstate commerce, as states' reporting requirements widely vary, resulting in consumers receiving limited and varied information to guide their decisions on whether and how to engage in daily fantasy sports contests.

Each state's regulatory model for daily fantasy sports related to operator registration requirements and consumer protection mechanisms, if enacted, is detailed in the following sections. 


\section{Arkansas}

Arkansas requires daily fantasy sports operators to pay an $8 \%$ tax on their gross paid fantasy sports game revenues (Paid Fantasy Sports Games, 2017).

\section{Colorado}

To operate a daily fantasy sports business in Colorado, an operator must become registered or licensed within the state, depending upon the size of the operator's business. Operators with less than 7,500 players in Colorado must register with the state, but are not required to become licensed or submit an annual audit. Operators with more than 7,500 players in Colorado must become licensed by the state, pay a licensing fee, and perform an annual independent audit. Both types of daily fantasy sports operators are precluded from having "officers, directors or general partners who have been convicted or entered pleas of nolo contendere or guilty to a felony" (Fantasy Contests, 2016).

Colorado's statute also contains a number of consumer protections, including: disallowing the daily fantasy sports operator's employees and their families from competing in the operator's contests; disallowing the sharing of confidential information that could affect contests until the information is made publicly available; disallowing individuals from competing in contests in which they are athletes or officials in the game; requiring verification that participants are over 18 years old; allowing self-restriction to access; limiting entries; limiting the amount of accounts a player can maintain; requiring daily fantasy sports operators to disclose terms and conditions; distinguishing players' statuses as experienced; prohibiting the use of scripts; and requiring the segregation of fantasy contest player funds from the operator's operational funds (Fantasy Contests, 2016).

\section{Delaware}

Delaware requires daily fantasy sports operators to register with the state. With respect to consumer protection mechanisms, registered operators are required to: prohibit minors from participating in contests; allow participants to self-exclude; not target advertisements to prohibited participants, minors, or self-excluded players; include information for assistance for compulsive play; limit players to one active account; disclose the number of entries a player may submit in each contest and limit entries in certain contests; disclose the total number of entries allowed for each contest; make known the value of prizes and awards prior to the contest; not mislead participants on the chances of winning and number of winners; provide explanations for contest play and how to identify skilled players; attach symbols to highly experienced players in contests; prohibit the use of scripts; provide players' account history information; protect the privacy and online security of players; and segregate players' funds from the operating funds of the company (Delaware Interactive Fantasy Contests Act, 2017).

\section{Indiana}

Indiana requires daily fantasy sports operators to register within the state and pay an initial fee of at least $\$ 50,000$. A $\$ 5,000$ renewal fee is due annually and licensees undergo a compliance investigation every three years. Licensed daily fantasy sports companies must submit to annual financial audits completed by certified public accountants (Paid Fantasy Sports, 2016). 
Indiana prohibits daily fantasy sports operator employees, owners, directors, officers, and their families from competing in paid fantasy sports games and sharing confidential information that could affect game play until it is publicly available. It has adopted age limits and self-exclusion. Indiana prohibits individuals playing in or officiating a game from participating in a daily fantasy contest related to that game. Daily fantasy sports operators are required to segregate players' funds from the operating funds of the company (Paid Fantasy Sports, 2016).

\section{Maine}

Maine requires daily fantasy sports operators to become licensed. Applicants pay a one-time application fee. Those receiving licensure pay a $\$ 2,500$ fee if their gross fantasy contest revenues the prior year equaled or were greater than $\$ 100,000$. Operators generating these revenues must also submit to an annual audit conducted by a certified public accountant. Operators with lesser revenues do not have to pay the licensing fee or submit to an audit. However, both types of operators must submit an annual report to the state related to accounts from participants in Maine held by the operator. Licenses are renewed annually (Regulation of Fantasy Contests, 2017).

Maine prohibits daily fantasy sports operators, directors, officers, employees, and their relatives from participating in contests provided by the operator. It prohibits the sharing of confidential information that could affect the outcome of play until it is made publicly available and the use of third-party scripts. Maine disallows individuals playing in or officiating a game from participating in a daily fantasy contest related to that game. Maine has adopted age limits and self-exclusion. Players are only allowed to have one active account per operator site. Operators are required to provide players with information on: responsible play and compulsive behavior; how to participate in fantasy contests; how to identify highly experienced competitors; the number of allowed entries per player per contest; and state and federal tax obligations on certain winnings. Highly experienced players must be designated on the operators' platforms and operators must offer contests limited to beginners. Operators cannot make misleading or inaccurate statements related to the likelihood of winning or target minors or self-excluded individuals with advertisements. Finally, operators must implement a complaint system for players, respond to any complaints within 48 hours, and maintain records of player accounts for up to five years. Operators in Maine are required to protect players' privacy and security, and to segregate players' funds from the operating funds of the company (Regulation of Fantasy Contests, 2017).

\section{Maryland}

Maryland requires any daily fantasy sports operator that offers contests in its state to register with the state. Operators are required to submit to an annual independent audit conducted by a certified public accountant (Fantasy Sports Competition Regulations, 2017).

Maryland prohibits daily fantasy sports employees, principals, officers, directors, contractors, and their immediate relatives from participating in contests provided by the operator. However, Maryland allows these individuals to participate in contests for testing purposes using clearly marked accounts if they 
fully disclose their participation to other participants in the contest and aren't eligible to win a prize. Maryland disallows individuals playing in or officiating a game from participating in a daily fantasy contest related to that game (Fantasy Sports Competition Regulations, 2017).

Maryland has adopted age limits and self-exclusion. Daily fantasy sports operators' advertisements cannot portray minors, unless they are professional athletes; students; schools and colleges; or schools and college settings. However, nothing in Maryland's statute prohibits advertising to minors or self-excluded individuals (Fantasy Sports Competition Regulations, 2017).

Operators are required to provide players with information on the number of allowed entries per player per contest. Maryland limits the amount of money participants can deposit into a daily fantasy sports account each month. Daily fantasy sports operators are not allowed to extend participants credit to use in daily fantasy sports contests. Additionally, participants may only maintain one username per daily fantasy sports operator site (Fantasy Sports Competition Regulations, 2017).

Highly experienced players must be designated on the operators' platforms and operators must offer contests limited to beginners. The state prohibits the use of third-party scripts. Operators in Maryland must protect players' data and are required to segregate players' funds from the operating funds of the company (Fantasy Sports Competition Regulations, 2017).

\section{Massachusetts}

Massachusetts prohibits daily fantasy sports employees, principals, officers, directors, contractors, and their immediate relatives from participating in contests provided by the operator, unless they play in private contests and their affiliation with the operator is clearly disclosed to each player. Massachusetts also allows these individuals to participate in contests for testing purposes using clearly marked accounts. Individuals using test accounts aren't eligible to win a prize. Massachusetts prohibits the sharing of confidential information that could affect the outcome of play to any person permitted to engage in daily fantasy sports contests before the information is made public. It prohibits individuals playing in or officiating a game from participating in a daily fantasy contest related to that game (Daily Fantasy Sports Contest Operators in Massachusetts, 2016).

Massachusetts has adopted age limits and requires operators to make available, prominently publish, and facilitate parental control procedures. It has also recognized self-exclusion, and allows third parties to exclude others from participation if the third party shares the credit card for the daily fantasy sports account. The state requires daily fantasy sports operators to provide employees information on problem gaming. Daily fantasy sports operators' advertisements cannot portray minors, unless they are professional athletes; students; schools and colleges; or schools and college settings. Daily fantasy sports operators cannot target minors with advertisements, or host promotional activities at schools and colleges in Massachusetts. They also may not target self-excluded individuals with advertisements. Advertisements must contain information related to assistance for problem gamers (Daily Fantasy Sports Contest Operators in Massachusetts, 2016). 
Operators must publish the number of allowed entries per player per contest and the state places limits on the number or entries per contest, based on the number of participants per contest. The state has also adopted regulations related to operators' abilities to offer free or discounted entries. Massachusetts law limits participants to one username per each daily fantasy sports operator site. Massachusetts limits the amount of money participants can deposit into a daily fantasy sports account each month. Operators must disclose potential tax liabilities to players. Representations about winnings must be accurate, not misleading, and capable of substantiation at the time made. Material terms of any promotional offers made by daily fantasy sports operators must be fully and accurately disclosed at the time of advertisement (Daily Fantasy Sports Contest Operators in Massachusetts, 2016).

Operators are required to provide players with information on contest play and how to identify highly experienced players. Highly experienced players must be designated on the operators' platforms and operators must offer contests limited to beginners. The state has banned use of third-party scripts (Daily Fantasy Sports Contest Operators in Massachusetts, 2016).

Operators in Massachusetts are required to segregate players' funds from the operating funds of the company. They must also protect players' data. Operators are required to maintain information related to players' accounts, winners of contests, and advertisements. Operators must publish procedures under which players can issue complaints and must respond to said complaints within 10 days. All complaints must be retained for a period of time (Daily Fantasy Sports Contest Operators in Massachusetts, 2016).

\section{Mississippi}

Mississippi's regulations apply to daily fantasy sports operators with more than 100 players within the state. The state requires daily fantasy sports operators to become licensed. Applicants for licensure must pay a \$5,000 application fee and licenses are valid for three years. Licensees pay up to $8 \%$ of their net Mississippi revenues to the Mississippi Department of Revenue. Operators are required to submit to an annual independent audit (Fantasy Contest Act, 2017).

Mississippi prohibits daily fantasy sports employees and relatives in their households from participating in contests provided by the operator. It prohibits the sharing of confidential information that could affect the outcome of play until it is made publicly available. Mississippi disallows individuals playing in or officiating a game from participating in a daily fantasy contest related to that game. Mississippi has adopted age limits and self-exclusion. Operators may not advertise toward minors and self-excluded individuals (Fantasy Contest Act, 2017).

Operators are required to provide players with information on the number of allowed entries per player per contest. The state limits the number of entries per contest, based on the number of participants per contest. Representations about winnings may not be unfair or misleading, and specific content requirements must be met when making such representations (Fantasy Contest Act, 2017).

Highly experienced players must be designated on operators' platforms in Mississippi. Operators must publish introductory procedures for players. Operators in Mississippi are required to segregate players' funds from the operating funds of the company (Fantasy Contest Act, 2017). 


\section{Missouri}

Missouri requires daily fantasy sports operators to become licensed. Daily fantasy sports operators pay an initial application fee of the lower of $\$ 10,000$ or $10 \%$ of the applicant's prior year's net revenue. Applicants must pay the cost, up to $\$ 10,000$, of Missouri investigating their operations during the application process. This cost may be waived in part or in whole upon showing an undue burden. Upon becoming licensed, operators with annual net revenues exceeding $\$ 2$ million must pay a $\$ 5,000$ annual license renewal fee. Operators with net revenues between $\$ 1$ million and $\$ 2$ million pay an annual license renewal fee of $\$ 2,500$; operators with net revenues between $\$ 250,001$ and $\$ 999,999$ pay $\$ 1,000$; and those with net revenues below $\$ 250,000$ do not pay a renewal fee. Additionally, all operators pay an operation fee to the state equal to $6 \%$ of their net revenue from the previous year. Operators with annual net revenues exceeding $\$ 250,000$ are required to submit to an annual independent audit conducted by a certified public accountant (Fantasy Sports Contests, 2017).

Missouri prohibits daily fantasy sports employees, principals, officers, directors, or contractors from participating in any fantasy sports contests open to the public. Missouri disallows individuals playing in a game from receiving a prize from a daily fantasy contest related to that game (Fantasy Sports Contests, 2017).

Missouri has adopted age limits and self-exclusion. The state requires sites to publish parental control procedures and allow parents to exclude minors from contests. Daily fantasy sports operators must provide links on their websites to compulsive behavior websites. Daily fantasy sports operators' advertisements cannot target minors or self-excluded individuals. They also cannot portray minors, students, schools, or colleges (Fantasy Sports Contests, 2017).

Participants may only maintain one username per daily fantasy sports operator site and must register with the operator prior to participating in contests on the site. The participant registration process requires daily fantasy sports operators to validate participants' ages and states of residence. Missouri requires operators to allow players to close accounts at any time and to allow players access to their play history and account details. Daily fantasy sports operators are not allowed to extend participants credit to use in daily fantasy sports contests. Daily fantasy sports operators cannot misrepresent the frequency or extent of winning in advertisements (Fantasy Sports Contests, 2017).

Highly experienced players must be designated on the operators' platforms and operators must offer contests limited to beginners. The state prohibits the use of third-party scripts. Operators in Missouri are required to segregate players' funds from the operating funds of the company. Operators must deposit a player's winnings into his or her accounts within 48 hours or mail winnings within five business days. The law also specifies the reserve amount daily fantasy sports operators must maintain (Fantasy Sports Contests, 2017).

\section{New Hampshire}

New Hampshire requires daily fantasy sports operators to register with the state. Operators are required to submit to an annual independent audit. New Hampshire prohibits daily fantasy sports employees and their relatives from participating in contests provided by the operator. It prohibits the sharing of 
confidential information that could affect the outcome of play until it is made publicly available and the use of third-party scripts. New Hampshire disallows individuals playing in or officiating a game from participating in a daily fantasy contest related to that game (Fantasy Sports Contests, 2017).

New Hampshire has adopted age limits and self-exclusion. Operators are required to provide players with information on responsible play, compulsive behavior, and player history. Operators cannot target minors, self-excluded individuals, or college students with advertisements (Fantasy Sports Contests, 2017).

The state requires operators to provide players with information on the number of allowed entries per player per contest. Highly experienced players must be designated on the operators' platforms and operators must offer contests limited to beginners. Operators in New Hampshire are required to segregate players' funds from the operating funds of the company (Fantasy Sports Contests, 2017).

New Jersey

New Jersey requires any daily fantasy sports operator that offers contests with entry fees in its state to apply for a permit. A permitting fee related to New Jersey's costs in regulating the daily fantasy sports industry is charged. In addition to the permitting fee, operators pay an operations fee each quarter equal to $10.5 \%$ of their quarterly daily fantasy sports gross revenues. Operators are required to submit to an annual independent audit conducted by a certified public accountant (Provides for regulation of fantasy sports activities in New Jersey, 2017).

New Jersey has adopted age limits and self-exclusion. New Jersey requires operators to establish and disclose all prizes to participants ahead of contests. It prohibits the sharing of confidential information that could affect the outcome of play until it is made publicly available. Operators must disclose the number of entries players may submit. Operators in New Jersey are required to segregate players' funds from the operating funds of the company (Provides for regulation of fantasy sports activities in New Jersey, 2017).

\section{New York}

New York requires daily fantasy sports operators to register with the state. Registrations are valid for three years. Operators pay a tax of $15 \%$ of the revenues they generate within the state to New York annually. Operators also pay an additional tax of $.05 \%$ of their annual New York revenues, not to exceed $\$ 50,000$, annually (Interactive Fantasy Sports, 2016).

New York has adopted age limits and self-exclusion. Operators are required to publish parental control procedures and information on assistance for compulsive play. Operators cannot target minors and self-excluded individuals with advertisements (Interactive Fantasy Sports, 2016).

New York limits players to one active account per daily fantasy sports operator site. Operators are required to maintain information on all accounts for a period of five years. Operators are required to provide players with information on: the value of any prize in advance of a contest; the total number of entries allowed per each contest; and the number of allowed entries per player per contest. Statements in advertising on the chances of winning a contest cannot be inaccurate or misleading (Interactive Fantasy Sports, 2016). 
Operators must provide introductory playing procedures for players. Highly experienced players must be designated on operators' platforms. New York prohibits the use of third-party scripts. The state requires operators to adopt procedures to protect players' privacy and online security. Operators in New York are required to segregate players' funds from the operating funds of the company. Operators must display complaint procedures on their websites and respond to complaints made within 48 hours of receipt (Interactive Fantasy Sports, 2016).

\section{Pennsylvania}

Pennsylvania requires any daily fantasy sports operator that offers contests in its state to become licensed. The fee to apply for a license is based on the cost necessary for Pennsylvania to enforce its daily fantasy sports regulations. If a license is awarded, operators must pay a $\$ 50,000$ license fee. The license is valid for five years. The license renewal fee is $\$ 10,000$. Licensed operators must pay a tax of $15 \%$ of their monthly fantasy contest revenues to the state. Operators generating more than $\$ 250,000$ in revenue per year must submit to an annual independent audit conducted by a certified public accountant (Fantasy Contests, 2017).

Pennsylvania prohibits daily fantasy sports employees, principals, and relatives living in their households from participating in daily fantasy sports contests. Pennsylvania disallows individuals playing in a game from participating in a daily fantasy sports contest related to that game. Operators cannot share confidential information that could affect contests with third parties until the information is publicly available (Fantasy Contests, 2017).

Pennsylvania has adopted age limits and self-exclusion. Operators in Pennsylvania cannot advertise to self-excluded individuals. Operators must provide a phone number to access drug and alcohol treatment services and place compulsive and problem play notices on their sites (Fantasy Contests, 2017).

Pennsylvania requires players to establish accounts with daily fantasy sports operators to participate in contests. Daily fantasy sports operators are not allowed to extend participants credit to use in daily fantasy sports contests. Operators are required to provide players with information related to contest prizes prior to the beginning of a contest and the number of allowed entries per player per contest. Participants' identities must be verified prior to engaging in a contest by validating their usernames and passwords. The state prohibits the use of third-party scripts (Fantasy Contests, 2017).

Operators in Pennsylvania must offer contests limited to beginners. Pennsylvania requires operators to segregate players' funds from the operating funds of the company. They also must protect players' personal and financial information. The state requires daily fantasy sports operators to develop procedures to handle player complaints (Fantasy Contests, 2017).

\section{Tennessee}

Tennessee requires operators to become licensed within the state. Operators are required to submit to an annual independent audit. Tennessee prohibits daily fantasy sports employees, contractors, and their immediate relatives from participating in public daily fantasy sports contests provided by any operator. However, Tennessee allows these individuals to participate in contests using 
clearly marked accounts if they fully disclose their participation to other participants in the contest or for testing purposes. It prohibits the use of thirdparty scripts. Tennessee disallows individuals playing in or officiating a game from participating in a daily fantasy contest related to that game. It prohibits operators from disclosing confidential information to third parties that could affect the outcome of a contest before that information is made public (Fantasy Sports Act, 2016).

Tennessee has adopted age limits and self-exclusion. Operators are required to publish parental control procedures and allow parents to exclude their children from contests. Operators must publish compulsive gambling assistance information on their sites. Operators' advertisements cannot target minors nor can they depict minors, students, schools, or colleges. Operators cannot target self-excluded individuals with advertisements. Advertisements must accurately represent the chances and number of persons winning. Advertisements must disclose assistance information for compulsive gamblers when feasible (Fantasy Sports Act, 2016).

Tennessee limits the amount of money players can deposit into their accounts for play. Players are limited to one account per site. Operators are required to maintain records of all player accounts and retain said records for five years. Tennessee requires operators to limit the number of entries per contest per player (Fantasy Sports Act, 2016).

Operators are required to provide beginner players with introductory procedures and information on how to identify highly experienced players. Highly experienced players must be designated on the operators' platforms and operators must offer contests limited to beginners. Operators in Tennessee are required to segregate players' funds from the operating funds of the company (Fantasy Sports Act, 2016).

\section{Vermont}

Vermont requires daily fantasy sports operators to register with the state. Operators must pay an annual registration fee of $\$ 5,000$. Operators are required to submit to an annual independent audit. Vermont prohibits daily fantasy sports employees and their immediate relatives from participating in public daily fantasy sports contests provided by any operator. Vermont disallows individuals playing in or officiating a game from participating in a daily fantasy contest related to that game. It prohibits operators from disclosing confidential information to unauthorized persons (Fantasy Sports Contests, 2017).

Vermont has adopted age limits and self-exclusion. Operators must publish compulsive gambling assistance information on their sites. Operators' advertisements cannot target or depict minors, students, schools or colleges, or school or college settings. Advertisements must accurately represent the chances of winning. Advertisements must disclose assistance information for compulsive gamblers (Fantasy Sports Contests, 2017).

Operators cannot issue credit to players. Players are limited to one account per site. Operators must provide players access to information related to their play and account for a period of six months. Vermont requires operators to limit the number of entries per contest per player and inform players of the number 
of entries per game. Operators in Vermont are required to segregate players' funds from the operating funds of the company. Vermont prohibits the use of third-party scripts (Fantasy Sports Contests, 2017).

\section{Virginia}

Virginia requires daily fantasy sports operators to register with the state. The state sets a one-time application fee that must be paid by all registration applicants, which is presently set at $\$ 50,000$. Operators are required to submit to an annual independent audit conducted by a certified public accountant (Fantasy Contests Act, 2016).

Virginia prohibits daily fantasy sports employees and their immediate relatives from participating in public daily fantasy sports contests provided by the operator. Virginia disallows individuals playing in a game from participating in a daily fantasy contest related to that game. It prohibits operators from disclosing confidential information that could affect the outcome of a contest to third parties before the information is publicly available (Fantasy Contests Act, 2016).

Virginia has adopted age limits and self-exclusion. Virginia requires operators to limit the number of entries per contest per player and inform players of the number of entries per game. Operators in Virginia are required to segregate players' funds from the operating funds of the company (Fantasy Contests Act, 2016).

\section{The 20th Century Securities Industry and the 21st Century Daily Fantasy Sports Industry: Examining the Need to Federally Regulate Daily Fantasy Sports}

Relevant similarities exist between the securities industry in the early 20th century and the 21 st century daily fantasy sports industry. These similarities relate to the industries' speculative natures; expansive early advertising campaigns; allegations of insider trading; and concerns over the breadth of information provided to consumers to assist them in their decisions of whether and how to engage with the industries.

One notable similar feature of the stock market and daily fantasy sports is both industries present consumers with an opportunity to earn the greatest amount of income from investments or wagers that outperform their expected values. Similar to the stock market, daily fantasy sports players have the best chances to earn money on their wagers by spending the least amount of money on players who generate the highest amount of positive production (Feeney, 2016; Macey \& Miller, 1991; Wallace, 2015).

Another similarity between the two industries is the heavy reliance by both on expansive advertising campaigns early in their existence to attract consumers to their offerings. In the wake of these campaigns, political leaders questioned the claims advertised by both industries over fears that they misled consumers on the likelihood and scope of winning and offered fraudulent promotions (Baker, 2015; Berzon, 2016; Macey \& Miller, 1991; Van Natta Jr., 2016). In fact, following allegations of insider trading by DraftKings and FanDuel employees in 
2015, the New York attorney general began investigating the daily fantasy sports industry. The investigation resulted in a lawsuit, which was ultimately settled for $\$ 12$ million, alleging false advertising against DraftKings and FanDuel. The basis of the lawsuit was an allegation that the companies' advertisements:

$[\mathrm{m}]$ isled casual and novice players about the substantial advantages of high-volume and professional players ...; [g]ave false and misleading statistics in marketing and advertising about the likelihood that players will win cash prizes ...; [d] eceptively promised to match a player's initial deposit ...; [and $\mathrm{m}$ ]arketed its contests as harmless fun, while failing to disclose the danger to populations at risk for compulsive gaming and addiction or provide reasonable safeguards. (AG Schneiderman Announces, 2016, para. 7-10)

Perhaps the most startling similarity between the two industries in their infancies, though, is the limited amount of information both industries provide consumers ahead of placing investments or wagers. Like the securities industry in the early 20th century, the daily fantasy sports industry has faced questions related to the amount of information consumers are provided by operators to guide their decisions on wagers or whether to even participate in contests. Despite the interstate nature of the daily fantasy sports industry, there are not federal reporting guidelines or requirements for the industry. Thus, there is not an overarching standard of what information must be provided to daily fantasy sports participants prior to placing a wager. Rather, the amount of information provided to consumers by daily fantasy sports operators - most of which operate in interstate commerce-widely varies from state to state. As already discussed, some states do not require the reporting of any information to consumers by daily fantasy sports operators, while others require significant warnings and information to be given to consumers (Daily Fantasy Sports: Issues and Perspectives, 2016).

The lack of a reporting requirement has caused fear that consumers in interstate commerce are not fully aware of the risks that participating in daily fantasy sports presents. For instance, some who have studied the industry fear that daily fantasy sports contests present opportunities for beginning or amateur players to engage unwittingly against skilled players with significant data and algorithms at their use. Similarly, some question whether players understand the probability of winning a given contest, especially in the face of the number of entries that can be made in certain contests and the advantages held by others competing in the contests. These concerns mirror the concerns that Congress had for American consumers in enacting the Securities Act of 1933 and Securities Exchange Act of 1934, as the legislation focused on providing American consumers adequate enough information to inform their decisions on whether or not to engage with the industry (Daily Fantasy Sports: Issues and Perspectives, 2016; Macey \& Miller, 1991). 


\section{A Model Federal Framework to Regulate the Daily Fantasy Sports Industry}

A survey of individual states' daily fantasy sports regulatory models demonstrates variance in the amount of information operators are required to provide consumers. This variance limits the protection of consumers against being defrauded by operators and making uneducated wagering decisions in daily fantasy sports contests. Thus, similar to the securities industry in the early 20 th century, "[i]n spite of many state statutes the public ... [may] sustain ... severe losses through practices neither ethical nor honest on the part of many persons and [daily fantasy sports companies]" (Ellenberger \& Mahar, 1973, p. 937). Given the wide reach of the daily fantasy sports industry across interstate commerce, Congress must determine how to regulate the industry at the federal level to best protect American consumers. Presently, three options exist: (1) maintain the status quo, (2) enforce pre-existing regulations against daily fantasy sports operators, or (3) amend the UIGEA to exclude daily fantasy sports and enact regulations.

\section{Maintain the Status Quo}

PAPSA and the UIGEA present hurdles for Congress when it comes to regulating the daily fantasy sports industry at the federal level. Any attempt by Congress to specifically regulate the industry will likely require it to amend the laws to: legalize sports gambling, declare daily fantasy sports to not be gambling, or exempt daily fantasy sports from the purview of the UIGEA.

Congress may be reticent in taking any of these actions, as demonstrated by a comment by New Jersey congressman Frank Pallone during a congressional hearing on daily fantasy sports in 2016 . When asking a witness about the ability of small daily fantasy sports companies to comply with state regulations, Pallone remarked, "And is there a way to do something at the Federal level that doesn't force States who don't want fantasy sports or gaming to allow it?" (Daily Fantasy Sports: Issues and Perspectives, 2016, p. 85).

Recognizing potential contradictions with existing federal law and seeing states take different approaches to legalizing and regulating daily fantasy sports, Congress may choose to remain silent on the issue of whether daily fantasy sports are legal and subsequently not regulate the industry.

\section{Enforce Pre-Existing Regulations Against Daily Fantasy Sports Operators}

Should Congress decide to not speak directly on the legality of daily fantasy sports and regulate the industry, the federal government could enforce pre-existing federal laws against the daily fantasy sports industry to protect consumers.

The Federal Trade Commission Act can be enforced against daily fantasy sports operators in interstate commerce that engage in deceptive acts. Section 45 (a) (1) of the Federal Trade Commission Act declares it unlawful for corporations to use "unfair or deceptive acts or practices in or affecting commerce" (Unfair methods of competition unlawful, 27, $\S 45$ (a) (1)). The Federal Trade Commission could enforce Section 45 (a) (1) against daily fantasy sports operators who deceive 
consumers on information related to insider trading, highly skilled players' participation in contests, the likelihood of winning contests, and the value of prizes awarded to contest winners (Unfair methods of competition unlawful, 2017).

Similarly, the Federal Trade Commission Act could also be enforced against daily fantasy sports operators who engage in false advertising. Section 52 of the Federal Trade Commission Act outlaws the dissemination of false advertisements by any means that is likely to induce a purchase effecting commerce. Misleading statements on the likelihood of success in daily fantasy costs could arguably be prosecuted under this section. The dissemination of false advertisements under Section 52 of the Federal Trade Commission Act is an unfair or deceptive act or practice under Section 45 of the Federal Trade Commission Act (Dissemination of false advertisements, 2017).

\section{Amend the UIGEA to Exclude Daily Fantasy Sports and Enact Regulations}

Although federal mechanisms exist to prevent unfair and deceptive acts and false advertising in the daily fantasy sports industry, to provide adequate safeguards for consumers participating in daily fantasy sports contests, regulation for the industry must exist at both the state and federal levels. The rationale for this is two-fold. First, daily fantasy sports contests fall under the scope of Congress's legislative power to regulate interstate commerce, as many contests involve participants in multiple states competing in contests hosted by operators located across state lines. Second, as demonstrated by the regulation of the securities industry, states take varied approaches in regulating industries in interstate commerce. This can have negative effects on consumers. Enacting federal legislation would create consistency in how the industry is governed and what information is provided to consumers ahead of making wagers, so that Americans' losses from the industry are limited.

As previously discussed, states vary in their declarations of whether daily fantasy sports contests are legal within their borders. Some legalizing daily fantasy sports contests have enacted blue sky law types of legislation to regulate the daily fantasy sports industry. Unlike the blue sky laws of the early 20th century, however, the scope of the laws regulating the daily fantasy sports industry is less consistent, with much wider variances in the amount and type of information that must be provided by daily fantasy sports operators.

In large part, blue sky laws for securities required registration within a state and reporting by the securities provider, while disallowing the sale of fraudulent securities. While some consistencies exist in how states regulate the daily fantasy sports industry, the biggest disparity between states' regulations for the daily fantasy sports industry relates to the amount and breadth of information consumers are provided. This disparity acts against the caveat emptor theory adopted by Congress in the Securities Act of 1933, and rather, puts the onus on consumers to decipher with limited information the validity and likelihood of success of the daily fantasy sports contests they enter (McGreevy, 2016; Smith \& Spehler, 2016; Woodward, 2016).

As states adopt differing regulatory mechanisms offering consumers varied levels or no protection from the daily fantasy sports industry and increasing 
numbers of Americans engage in daily fantasy sports contests, Congress should amend the UIGEA to clarify daily fantasy sports contests' legality. Since daily fantasy sports contests did not exist in 2006 when the UIGEA was passed, it is unclear whether Congress's exemption of fantasy sports from the definition of "bet and wager" encompasses daily fantasy sports contests. Amending the law to clarify the definition would create greater consistency nationwide as to the legality of daily fantasy sports contests. Subsequently, this clarification could spur more states to enact blue sky law types of regulatory systems aimed at protecting consumers engaged in daily fantasy sports contests.

Additionally, if Congress amended the UIGEA or drafted new legislation declaring daily fantasy sports contests legal, it could enact additional legislation to regulate the industry to provide the greatest level of safeguards for American consumers. Using its power to regulate interstate commerce, Congress could enact a law similar to the Securities Act of 1933, which imposed consumer protection regulations upon sellers of securities across the entire United States. It would be prudent of Congress to pass legislation imposing age limits on players; allowing players to self-exclude from participation; requiring providers to submit reports providing consumers information on the risks involved and likelihood of success in participating in daily fantasy sports; and disallowing fraud in the carrying out of daily fantasy sport sites and/or contests.

While many states currently regulating the daily fantasy sports industry have measures in place to address the proposed federal regulatory mechanisms mentioned, some states' mechanisms are much broader and further reaching. Thus, where Congress could provide the most clarity in this regard is in specifying the areas in which daily fantasy sports operators must provide information to consumers in every state. To determine the type of information that should be reported, Congress should follow the standard adopted by its predecessors in enacting the Securities Act of 1933 and move away from the principle of caveat emptor and to a perspective of consumers' decisions being the most prudent when they are based on the greatest amount of information.

Thus, state regulations like those enacted in New Hampshire, New York, and Pennsylvania should serve as the model for any future federal regulation of the daily fantasy sports industry. These states' regulations provide consumers with the most information, while still allowing them to make individual decisions on whether to participate. For consumers to make the most guided decision on whether and how to play daily fantasy sports, regulations must require daily fantasy sports operators to provide information on: instructions for play; identifying highly skilled players; the number of allowed and total entries per contest; the total prize amount per contest; where to access resources for responsible play and compulsive behavior; and how to lodge complaints with the daily fantasy sports operator. Information in these areas allows consumers to most fully weigh the risks versus rewards of daily fantasy sports play.

Congress passing federal legislation of this type would ensure daily fantasy sports players receive necessary consumer protection safeguards, regardless of the state in which they reside. Since the reach of daily fantasy sport contests does not presently reach the level of the sale of securities in the early 20th century, it would be unnecessary for Congress to enact a bill similar to the Securities Exchange Act of 1934 to create a separate federal agency to execute the bill. 
Rather, like the Securities Act of 1933, Congress could charge the Federal Trade Commission with executing the bill.

\section{Conclusion}

More Americans than ever are participating in daily fantasy sports contests. As the daily fantasy sports industry enjoys significant growth, states continue to determine whether the contests are legal, and if so, how to regulate the industry to best protect consumers. Federal legislation first clarifying the legality of daily fantasy sport contests and then federally regulating the industry would end states' confusion, while providing necessary protection for American consumers.

\section{References}

A. G. Schneiderman announces $\$ 12$ million settlement with Draftkings and Fanduel (2016, October 25). Retrieved from https://ag.ny.gov/press-release/ag-schneiderman-announces-12-million-settlement-draftkings-and-fanduel

Baker, G. (2015, November 11). DraftKings and FanDuel spend millions on fantasy sport advertising, and it works. The Seattle Times. Retrieved from http://www.seattletimes.com/sports/ seahawks/draftkings-and-fanduel-spend-millions-on-fantasy-sports-advertising-and-it-works/

Basenese, L. (2013, November 7). My secret to always buying low and selling high. Wall Street Daily. Retrieved from http://www.wallstreetdaily.com/2013/11/07/value-investing/

Berzon, A. (2016, August 1). Fantasy-sports sites curtail ad spending. The Wall Street Journal. Retrieved from http://www.wsj.com/articles/fantasy-sports-rivals-slice-ad-spending-1470052800

Daily fantasy sports contest operators in Massachusetts, 940 Code Mass. Regs. $§ 34.01-34.18$ (2016).

Daily fantasy sports investment \& acquisition tracker. (2015, December 21). Legal Sports Report. Retrieved from http://www.legalsportsreport.com/dfs-investment-and-acquisition-tracker/

Daily fantasy sports: Issues and perspectives, Hearings before the Subcommittee on Commerce, Manufacturing and Trade, House of Representatives, 114th Cong. 48-51 (2016) (Testimony of Kurt Eggert).

Daily fantasy sports: Issues and perspectives, Hearings before the Subcommittee on Commerce, Manufacturing and Trade, House of Representatives, 114th Cong. 48-51 (2016) (Questioning of Congressman Pallone).

Delaware Interactive Fantasy Contests Act, Del. Code tit. 29, $\S § 863$ - 4865 (2017).

DFS partnership/sponsorship tracker. Legal Sports Report. Retrieved from http://www.legalsportsreport.com/dfs-sponsorship-tracker/

Dissemination of false advertisements, 15 U.S.C. $\$ 52$ (2017).

Drape, J., \& Williams, J. (2015, October 5). Scandal erupts in unregulated world of fantasy sports. The New York Times. Retrieved from http://www.nytimes.com/2015/10/06/sports/fanduel-draftkings-fantasy-employees-bet-rivals.html?smid=tw-bna\&_r=1

Drape, J. (2016, November 18). DraftKings and FanDuel agree to merge daily fantasy sports perations. The New York Times. Retrieved from https:/www.nytimes.com/2016/11/19/sports/ draftkings-fanduel-merger-fantasy-sports.html?_r=0

Edelman, M. (2015, December 23). Illinois Attorney General: Daily fantasy sports violate state law. Forbes.com. Retrieved from http://www.forbes.com/sites/marcedelman/2015/12/23/ illinois-attorney-general-daily-fantasy-sports-violates-state-law-not-feats-of-strength-orskill/\#18f6e4dle67f 
Edelman, M. (2016). Navigating the legal risks of daily fantasy sports: A detailed primer in federal and state gambling law. University of Illinois Law Review, Vol. 2016, 117-150. Retrieved from http://papers.ssrn.com/sol3/papers.cfm?abstract_id=2587362

Edelman, M. (2017). Recent silence on DraftKings and FanDuel merger may indicate antitrust concerns. Forbes.com. Retrieved from http://www.forbes.com/sites/marcedelman/2017/01/25/ recent-silence-on-draftkings-and-fanduel-merger-may-indicate-antitrust-concerns/\#155a$918 \mathrm{c} 32 \mathrm{a} 7$

Edelman, M. (2017). Regulating fantasy sports: A practical guide to state gambling laws, and a proposed framework for future state legislation. Indiana Law Journal, 92, 675-683.

Ellenberger, J. S., \& Mahar, E. (1973). Legislative history of the Securities Act of 1933 and Securities Exchange Act of 1934. Law Librarians' Society of Washington, D.C., 4, 1933; 2914; 2983. Retrieved from http://heinonline.org/HOL/LandingPage?handle=hein.leghis/lhsv0004\&div=1

Fantasy Contest Act, MISS. CODE ANN. §§ 97-33-301 - 97-33-317 (2017).

Fantasy Contests Act, VA CODE ANN. §§ 59.1-566 - 59.1-570 (2016).

Fantasy Contests, COLO. REV. STAT. § 12-15.5 et. seq. (2016).

Fantasy Contests, 4 PA. CONS. STAT. $\S \S 301-342$ (2017).

Fantasy Sports Act, TENN. CODE ANN. §§ 47-18-5601 - 47-18-5611 (2016).

Fantasy Sports Competition Regulations, MD. CODE. CRIM. LAW §§ 12-114.01 - 12-114.14 (2017).

Fantasy Sports Contests, MO. REV. STAT. $\S 313.915 .1$ - 313.940 .1 (2017).

Fantasy Sports Contests, N.H. REV. STAT. ANN. §§ 287-H:1 - 287-H:3 (2017).

Fantasy Sports Contests, VT. STAT. ANN. tit. 9, §§ 116-4185 - 116-4190 (2017).

Feeney, P. (2016). Turning fantasy into regulatory reality: A new approach to daily fantasy sports laws. Columbia Journal of Law \& the Arts, 40, 105-139. https://doi.org/10.7916/D8B56XBS

Galka, M. (2015, October 9). Fantasy sports could pose real problem in Florida. WCTV.com. Retrieved from http://www.wctv.tv/home/headlines/Fantasy-Sports-Could-Pose-Real-Problemin-Florida-331849011.html

Hall, Z. (2016, September 22). Daily fantasy sports metrics for 2015: NBA, MLB made in-roads on NFL in entry fees. Legal Sports Report. Retrieved from http://www.legalsportsreport. com/7487/dfs-industry-money-in-2015/

Hanson, J. (2016, September 2). DraftKings, FanDuel master complaint lands in Mass. Court. Law360. Retrieved from https://www.law360.com/articles/835797/draftkings-fanduel-mastercomplaint-lands-in-mass-court

Harwell, D. (2015, October 12). All the reasons you (probably) won't win money playing daily fantasy sports. The Washington Post. Retrieved from https://www.washingtonpost.com/news/ the-switch/wp/2015/10/12/all-the-reasons-you-probably-wont-win-money-playing-daily-fantasy-sports/

Heitner, D. (2015, September 20). An abbreviated history of FanDuel and DraftKings. Forbes. com. Retrieved from http://www.forbes.com/sites/darrenheitner/2015/09/20/an-abbreviated-history-of-fanduel-and-draftkings/\#7c92alde2d12

How it works. (n.d.). FanDuel. Retrieved from https://www.fanduel.com/how-it-works

How to play. (n.d.). DraftKings. Retrieved from https://www.draftkings.com/help/how-to-play

H.R. Rep. No. 85, at 2 (1933).

Industry demographics. Fantasy Sports Trade Association. Retrieved from http://fsta.org/research/industry-demographics/

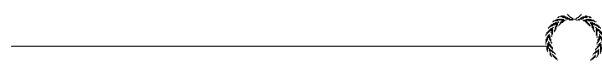


Interactive Fantasy Sports, N.Y. RAC. PARI-MUT. WAG. \& BREED Law $\S \S 14-1400$ - 14-1408 (2016).

Johnson, B., \& Salant, J. D. (2017). U.S. Supreme Court agrees to hear N.J. sports betting case. NJ.com. Retrieved from http://www.nj.com/politics/index.ssf/2017/06/supreme_court_agrees_ to_hear_nj_sports_betting_case.html

Keller, E. (1988). Introductory comment: A historical introduction to the Securities Act of 1933 and the Securities Exchange Act of 1934. Ohio State Law Journal, 49, 329-352. Retrieved from http://lawdigitalcommons.bc.edu/cgi/viewcontent.cgi?article=1815\&context=lsfp

Lee, S. (2015, October 8). How to win $\$ 350,000$ on FanDuel and the mathematics of daily fantasy sites. Newsweek. Retrieved from http://www.newsweek.com/draftkings-fanduel-mathematics-daily-fantasy-sites-381129

Legislative tracker: Daily fantasy sports. (2017). Legal Sports Report. Retrieved from http://www. legalsportsreport.com/dfs-bill-tracker

Macey, J., \& Miller, G. (1991). Origin of the Blue Sky Laws. Texas Law Review, 70, 348-397. Retrieved from http://digitalcommons.law.yale.edu/cgi/viewcontent.cgi?article=2679\&contex$\mathrm{t}=$ fss_papers

Mahoney, P. (2003). The origins of the Blue-Sky Laws: A test of competing hypotheses. The Journal of Law \& Economics, 46, 229-251. Retrieved from http://www.jstor.org/stable/10.1086/345580?seq=1\#page_scan_tab_contents. https://doi.org/10.1086/345580

McGreevy, P. (2016, January 27). Bill legalizing fantasy sports websites in California makes it out of state Assembly. Los Angeles Times. Retrieved from http://www.latimes.com/politics/la-polsac-fantasy-sports-20160126-story.html

Millman, C. (2009, May 13). Delaware allows sports betting. ESPN.com. Retrieved from http:// www.espn.com/espn/news/story?id=4162225

Needleman, S., \& Terlep, S. (2015, October 7). FanDuel, DraftKings ban employees from playing daily fantasy contests for money. The Wall Street Journal. Retrieved from http://www.wsj.com/ articles/fanduel-bans-employees-from-playing-daily-fantasy-contests-for-money-1444233537

Paid Fantasy Sports, Ind. Code § 4-33-24 (2016).

Paid Fantasy Sports Games, Ark. Code $§ 23-116-104$ (2017).

Professional and Amateur Sports Protection Act, 28 U.S.C. $§ 3702$ (2016).

Professional and Amateur Sports Protection Act, 28 U.S.C. $\$ 3704$ (2016).

Provides for regulation of fantasy sports activities in New Jersey, N.J. Rev. Stat $§ \S 5: 20-1-5: 20-3$ (2017).

Purdum, D. (2017, July 14). Planned merger between DraftKings, FanDuel is off. ESPN.com. Retrieved from http://www.espn.com/chalk/story/_id/20002903/in-abrupt-fashion-draftkingsfanduel-merger-off

Regulation of Fantasy Contests, Me. Stat. tit. 33, §§ 1103 - 1106 (2017).

Rovell, D. (2015, October 9). Class action lawsuit filed against DraftKings and FanDuel. ESPN. com. Retrieved from http://www.espn.com/chalk/story/_id/13840184/class-action-lawsuit-accuses-draftkings-fanduel-negligence-fraud-false-advertising

Satariano, A. (2015, January 15). How fake sports are turning man cave dwellers into millionaires. Bloomberg Businessweek. Retrieved from http://www.bloomberg.com/news/articles/2015-01-15/the-growing-world-of-moneymaking-fantasy-sports

Securities Act of 1933, 15 U.S.C. $§ 77$ et. seq. (1933).

Securities and Exchange Commmission. (1999, Dec. 21). Fast answers. U.S. Securities and Exchange Commission. Retrieved from https://www.sec.gov/fast-answers/answerssecworkhtm. html 
Securities Exchange Act of 1934, 15 U.S.C. § 78a et. seq. (1934).

Smith, M., \& Spehler, D. (2016, February 7). IN Focus: Could Indiana regulate daily fantasy sports? FOX59.com. Retrieved from http://fox59.com/2016/02/07/in-focus-could-indiana-regulate-daily-fantasy-sports/

Terlep, S. (2015, October 15). Daily fantasy sports sites ordered to shut down in Nevada. The Wall Street Journal. Retrieved from http://www.wsj.com/articles/daily-fantasy-sports-sites-orderedto-shut-down-in-nevada-1444956906

Unfair methods of competition unlawful; prevention by Commission, 15 U.S.C. $§ 45$ (2017).

Unlawful Internet Gaming Enforcement Act, 31 U.S.C. § 5362 (2016).

Unlawful Internet Gaming Enforcement Act, 31 U.S.C. § 5363 (2016).

Van Natta, D. (2016, August 24). Welcome to the big time. ESPN The Magazine. Retrieved from http://www.espn.com/espn/feature/story/_id/17374929/otl-investigates-implosion-daily-fantasy-sports-leaders-draftkings-fanduel

Wallace, N. (2015, December 11). Daily fantasy sports: Gambling or investment. Fox Business. Retrieved from http://www.foxbusiness.com/markets/2015/12/11/daily-fantasy-sports-gambling-or-investment.html

Whaley, S. (2016, June 8). Gaming Board votes for return of daily fantasy sports betting. Las Vegas Review Journal. Retrieved from http://www.reviewjournal.com/business/casinos-gaming/ gaming-board-votes-return-daily-fantasy-sports-betting

Woodward, C. (2016, March 25). Mass. finalizes new rules for fantasy sports games. Boston Globe. Retrieved from https://www.bostonglobe.com/business/2016/03/25/massachusetts-finalizes-new-rules-for-fantasy-sports-bans-college-games-players-under/POXUtUYBN2ITD2tqIRPs0O/story.html 